\title{
Convergence and divergence of biosecurity and biodiversity in China
}

\author{
Sidan Wang ${ }^{1}$ \\ Received: 26 December 2021 / Accepted: 9 February 2022 / Published online: 25 February 2022 \\ ○ The Institute of International and Strategic Studies (IISS), Peking University 2022
}

\begin{abstract}
The year 2020 witnessed a sharp increase in public attention to biological security (biosecurity) and biological diversity (biodiversity) governance. While COVID has triggered significant attention, this research chronicles and examines the development of biosecurity and biodiversity governance in China. The Copenhagen School's approach to securitization is employed as a theoretical framework to map the evolution of biosecurity and biodiversity. Through this lens, we find that biological governance has developed from ecological security to biological security, while biodiversity governance has been framed as involving various security concerns, including biological security. These fields have converged and diverged over time in China. This analysis reveals the potential for synergetic governance over biosecurity and biodiversity concerns while identifying policy gaps in China as well as in the fragmented institutional structure of global governance. This research also contributes to academic discussions surrounding associations between biosecurity and biodiversity governance.
\end{abstract}

Keywords Biosecurity $\cdot$ Biodiversity $\cdot$ Global governance $\cdot$ China $\cdot$ Securitization

\section{Introduction}

Triggered by the global COVID-19 outbreak, the year 2020 witnessed a sharp increase in public attention to biological security and biological diversity (biodiversity) governance. While the spread of infectious diseases is defined as an issue of biological security, such an unprecedented and urgent crisis of public health had not occurred since the 1918 influenza pandemic. A secondary security concern deals with the profound effects of the pandemic on global political, economic, and social activities. Global trade networks have been substantially damaged. Various energy crises have been observed, particularly in European countries. The pandemic has

Sidan Wang

wangsidan@cfau.edu.cn

1 Institute of International Relations, China Foreign Affairs University, Beijing, China 
thus extended a health crisis into the realms of economy, energy, and societal security. The potential risks and challenges of a global pandemic were underestimated before COVID-19. Pandemics were seen as a biological security risk, but it was common to emphasize traditional security risks, such as biological terrorists, as the dominant biological security concern. For this reason, it is important to uncover and understand how concepts related to biological security have been defined and have developed over time.

Although biological security has been identified as an urgent challenge across the world, biodiversity conservation fails to receive substantial public attention. The conservation refers to conserving biodiversity of genetical resources, species and ecosystems (CBD 2020). Biodiversity governance has lagged far behind climate action on the political agenda of the international community. For example, climate change has been a key theme across global political events, including G-7, G-20, and UN-based summits, while discussions about biodiversity conservation have been absent at such events.

Despite the conspicuous absence of such high-level discussions, some observers dubbed the year 2020 a super-year for the environment, simply because a range of significant events pertaining to global environmental governance, including Glasgow Climate Change Conference, the UN Ocean Conference, and the Kunming Biodiversity Conference (UNEP 2020a) were scheduled to take place. Unfortunately, these events were disrupted due to COVID-19, and the Kunming Biodiversity Conference was rescheduled to include a series of virtual meetings in October 2021 and face-to-face meetings in April 2022.

Three factors elevated the importance of biodiversity governance in 2021. First, China hosted a biodiversity conference and was committed to achieving a successful outcome. Second, the establishment of the Paris Climate Change Agreement has inspired stakeholders of biodiversity governance to adopt a global framework. Third, the pandemic continued to raise an urgent alarm about biological affairs, including biodiversity.

Pandemics have been widely defined as an issue of biological security, but biodiversity governance has failed to become an independent security issue. On one hand, the era of COVID-19 offers a window of opportunity for interlinking biological security and biodiversity governance so that they are understood as part of a broader category of biological concerns. On the other hand, biodiversity has its own security implications. For example, invasive alien species, identified as an urgent threat to biodiversity, can be categorized as an issue of biological security. But, the loss of biological resources and species threatens to decrease agricultural productivity, and is thus defined as a food security concern. Under the broadest definition, threats to biodiversity are understood as ecological and/or environmental security. Given the various interpretations of these issues, this article looks at how biodiversity has been linked to biological security. It shows the importance of examining the evolution of conceptual interactions between biosecurity and biodiversity governance.

Policies and political actions related to biodiversity and biosecurity can be identified in a broad sense, but research on the relationships between them is lacking. From a discursive perspective, the two different terms could be categorized into a set of frameworks to address biological issues. However, the differences between 
biological security and biodiversity governance might have different implications for both theoretical understanding and practical policies. Therefore, this research develops a main research question: How have biological security and biodiversity governance been discursively converging and diverging in the context of China?

To address the research question, the Copenhagen School's approach of securitization is employed as a theoretical and analytical framework. The theory of securitization refers to examining a dynamic process of politicalizing and securitizing the issues (Balzacq 2005; Buzan et al. 1998). Identifying securitization helps with mapping out the evolution of biosecurity governance and biodiversity conservation in China. The distinctive feature of this research is that it explores two different paths of securitizing. First, we observe how biological governance has been built into biosecurity and how biodiversity governance has been widely integrated into scientific discussions, prioritized for national policies, and adopted with a framework of ecological security in China. After offering theoretical support for the securitization model, we then observe how elements of biosecurity governance and biodiversity conservation have been converging and diverging in the institutional context of China.

This paper will now proceed as follows: Sect. 2 will show the evolution of biological security governance, and Sect. 3 will map the evolution of biological diversity governance of China. Section 4 contains an analysis of motivations for and obstacles to the convergence of biosecurity and biodiversity governance. Before the Conclusion, Sect. 5 will offer recommendations of relevant policies and institutional designs.

\section{Evolution of biological security governance of China}

China witnessed three phases of securitization in biological governance. Biological security is rooted in studies on the natural sciences and engineering. It has been the subject of academic discussions on laws, national security, and non-traditional security since the first few years of the twenty-first century. Biological security was, to a large extent, originally categorized as dealing with ecological and environmental issues. The principles of precaution, international cooperation, harmless utilization and cautious development-principles used to address environmental challengeswere identified as guidelines for addressing biological security issues (Wang and Yu 2003). Similarly, Zhang (2004) defined the term "ecological security" and identified five types of biological threats-namely, infectious disease, biological weapons, biotechnologies, invasive alien species, and management of biological laboratories. Following these discussions, the concept of biological security started to be adopted in the field of international studies in China. It was studied with the approaches of non-traditional security and human security (Zhou 2004).

The first phase of securitization demonstrates the rising importance of biological security across academic communities in China. There are three motives for this conceptual development. First, non-traditional security studies such as ecological security have been growing in prominence within academic agenda. The debate over genetically modified organisms (GMOs) developed in Western countries and 
travelled to China. This was identified as an emerging topic of biological security. Second, biological terrorists have been widely discussed since the $9 / 11$ terrorist attacks. This obviously triggered a wide range of concerns across the international community. Third, the outbreak of SARS (Severe Acute Respiratory Syndrome) sounded an alarm about the spread of infectious diseases in 2003. Controlling the spread of diseases is widely recognized as an important element of biological security.

The second phase of securitization involves establishing an overall national security approach in 2015. The approach raised the importance of non-traditional security, including ecological security. While biological security was not specifically defined in the approach, a wide range of security issues have been identified as top national political tasks. Liu (2020) linked biological security to resources, ecological, military, and technological security issues, as clarified in the national security approach. This linkage demonstrates the complexity of biological security. Resources security refers to biological resources such as traditional medicines; military security refers to biological weapons; technological security includes biotechnologies and biosafety. However, this categorization defines biological security in various, inconsistent ways. It is important to note that the threat of pandemics was vague in the approach until the global outbreak of COVID.

COVID-19 has explicitly triggered the third phase of securitization. It directed the world's attention to the importance of controlling the spread of infectious diseases. The unprecedented public health crisis required the establishment of the National Biosecurity Law and the inclusion of biological security into the national security approach. The Law went into effect April 15, 2021. It clarifies the seven activities to address biological security issues: infectious diseases and pandemics; biotechnology; pathogenic microbe laboratories; genetic resources and biological resources; invasive alien species (IAS) and biodiversity; antimicrobial resistance; and biological terrorist attacks and biological weapons (UNEP 2020b). China's recognition of biological security has shifted from a single security concern, e.g., GMOs, to a systemic approach to ecological, public health, and homeland security (Qin 2020). In this sense, the concept of national biological security governance has been discussed across the academic community in China (Wang 2020).

\section{Evolution of biological diversity governance of China}

Biodiversity governance in China developed in response to social and scientific discussions, international negotiations, and domestic policies. At first, scientific issues were dominant, particularly in an early stage of biodiversity governance. The primary issues included biotechnology, biosafety, and gene security. The management of GMOs and their impacts over food security have been widely discussed in China. On the domestic level, the National Environmental Administration of China released the National Framework of Biosecurity in 2000. This institutional arrangement demonstrates that biosecurity was identified as ecological and environmental security. At an international level, China proactively adopted the international agenda of biosecurity ratifying the Cartagena Protocol on Biosafety in 2005 (CBD 2021a). This 
shows an implication of China's participation in global biodiversity governance and its related international negotiations.

Second, the international negotiations of the Convention on Biological Diversity (CBD) have been seen as a driver for enhancing biodiversity governance in China. Shim and Shin (2020) identify local environmental actions, global governance, and international pressure as driving forces for the national implementation of global biodiversity governance. Since China signed the CBD at the 1992 Rio Earth Summit and adopted the Aichi Biodiversity Targets in 2010 (see Table 1), it has submitted its sixth national report on implementing the CBD and has been on track to achieve 16 of the 20 Aichi Biodiversity Targets created in 2010 (ADB 2021). This signals China's domestic actions on biodiversity conservation and its contribution to global biodiversity governance.

Third, China has accomplished a wide range of ecological conservation and restoration projects. For example, the Three-North Shelterbelt Programme was constructed in 1978 and has made a great contribution to tackling desertification and restoring ecosystems in China (FAO 2002). Also, China's actions offer a successful example for global biodiversity governance. The migration in 2021 of a family of wild Asian elephants in the Yunnan Province serves as a great example of China's wildlife conservation. Local governments ensured the safety of people and communities and mobilized resources to safely guide the migration of the elephant family

Table 1 Aichi biodiversity targets

\begin{tabular}{ll}
\hline Strategic goals & Targets \\
\hline A: mainstreaming biodiversity across government & 1. People's awareness \\
and society & 2. National and local development \\
& 3. Incentives, including subsidies, harmful to \\
biodiversity are eliminated
\end{tabular}

Source: CBD (2020) 
(CGTN 2021). This case can be an important example for other countries to follow and when making their own policies to address similarly urgent issues. It is also interesting to note that this migration occurred just before the Kunming Biodiversity Conference.

In line with the conceptual development of biological security, biodiversity governance also occurred in three phases of securitization in China. As Wang (2020) explains, China's biodiversity governance entered scientific discussions early, then developed as a set of important national policy issues in 2010, and entered the national security framework in 2014. Biodiversity issues had originally been linked to scientific studies on the diversity of species, gene resources, and ecosystems. In 2010, in response to global governance and international negotiations of biodiversity conservation, China's National Committee on Biodiversity Conservation released China's National Biodiversity Strategy and Action Plan (2011-2030) (MEP 2014).

The securitization of biodiversity governance refers to significant events of national security, such as the establishment of an overarching national security approach, the national legislation of biosecurity and the outbreak of the pandemic. In 2015, the overall national security community recognized the importance and urgency of ecological security. Referring to biodiversity governance as the conservation of genes, species, and ecosystems, those in the field categorized it as ecological security.

In 2020, the National Biosecurity Law was drafted and was designed to address various biosecurity challenges, including pandemics and invasive alien species (IAS). The legislation was mainly fueled by the COVID-19 outbreak. However, this critical moment signifies a closer link between biosecurity and biodiversity. The 2021 UN Biodiversity Conference in Kunming facilitated a discussion for the post2020 global biodiversity framework, achieved the Kunming Declaration, and outlined the 2050 Vision for Biodiversity (CBD 2021b). This increases the importance and urgency of biodiversity issues in the context of China's security policies.

In October 2021, China released the white paper "Biodiversity Conservation in China," which was intended to attach increased importance to biodiversity-related actions. The white paper categorized biodiversity issues as ecological security and biological security. The ecological security dimension of biodiversity includes building national parks, conserving natural habitats, setting ecological security barriers/areas such as the Qinghai-Tibet Plateau, maintaining ecological space, stabilizing ecosystems, and building national model cities for environmental protection. It was not surprising to see the importance placed on ecological security in the white paper. However, while elements of ecological security are identified across the document, the white paper also contained a section dedicated to improvements in biosecurity governance. China's biosecurity governance strategy identifies three main targets-IAS, GMOs, and biogenetic resources (SCIO 2021). First, controlling and managing invasive alien species, which can threaten the survival of local plants and wild animals, is an important element of biosecurity governance. This has a direct impact on the diversity of local species (e.g., agricultural products) and thus leads to various security concerns such as food security. Second, biodiversity governance requires improved administration of the GMOs. This refers to the use of biotechnology and a concern about biosafety. Third, the management of biogenetic resources is 
defined within biosecurity. For example, China has the authority to manage and collect data on the Traditional Chinese Medicine (TCM) resources. Conserving various biogenetic resources has inherent value for biosecurity governance.

\section{Convergence and divergence of biological security and biodiversity governance}

Biological governance evolved from ecological security to include biological security. Biodiversity governance was originally categorized as ecological security and has since been framed as including various other security concerns, including biological security. As researchers have observed, biosecurity and biodiversity have been constructed and securitized in their own ways. Institutionally, biodiversity governance has been dominated by the Ministry of Ecology and Environment, while biosecurity concerns seem to have been triggered by various issues and events, including ecological and agricultural concerns, biotechnologies, societal security, and pandemics. This evolution in governance implies the potential for more synergetic governance in the future. In this sense, this section discusses why and how biosecurity and biodiversity have converged and diverged over time.

\subsection{Motivations for convergence}

The concept of biological governance facilitates a foundation for convergence. While the concept of biological security has been derived from the development of technologies, biosafety, terrorist attacks, and public health crises, biodiversity governance has emerged through the evolution of global environmental governance such as the negotiations and implementation of the Convention on Biological Diversity (CBD). Discursively, the term "biological" has linked the two together. Institutionally, the environmental administrative agency set the National Framework of Biosecurity in 2000. This demonstrates that the environmental agency had been mainly in charge of biodiversity conservation and biological security.

However, as Table 2 demonstrates, the range of concerns identified in the National Biosecurity Law is broader than issues of biodiversity. Issues concerning

Table 2 Links between biosecurity and biodiversity

\begin{tabular}{ll}
\hline Biosecurity & Biodiversity \\
\hline Infectious diseases and pandemics & Plants, agricultural and food security \\
Biotechnology & Genetic diversity \\
Pathogenic microbe laboratories & N/A \\
Genetic resources and biological resources & Genetic diversity \\
The invasive alien species (IAS) and biodiversity & Species and ecosystems diversity \\
Antimicrobial resistance & N/A \\
Biological terrorist attacks and biological weapons & N/A \\
\hline
\end{tabular}


genetic resources, species, and food security are shared between biosecurity and biodiversity.

A link between genetic resources and genetic diversity is an important motivation for convergence. Biosecurity focuses on the ownership, utilization, and management of genetic and biological resources. China has sovereign authority over its own resources. Weakening and undermining this legal access to the resources is seen as a direct threat to national security. Biodiversity governance focuses on ensuring the diversity of genetic resources. Genetic diversity plays a key role in having a wide range of species and ecosystems. This requires effective management and conservation of genetic resources. In this sense, biosecurity and biodiversity have converged on securing genetic resources and diversity.

Similarly, a link between species diversity and IAS manifests as motivating convergence. Biodiversity governance prioritizes increasing the diversity of species. Species extinction has a devasting impact on ecosystems. Public policies have been required to address species extinction and the loss of biodiversity (Vadrot 2011, 29). Biosecurity makes a significant contribution to the conservation of species diversity while it focussing on controlling and managing the problems of the IAS. Invasive species have various links to ecosystems, environmental protection, and climate change. The uncontrolled spread of IAS could severely damage local ecosystems and cause the loss and extinctions of local species. Therefore, the spread and trading of species have been widely banned and strictly managed globally (Stoett 2010). Because IAS poses a threat to the species diversity, it has become an important theme of CBD negotiations.

Food security is a concern shared by biosecurity and biodiversity. Biosecurity governance emphasizes the issues of infectious diseases and pandemics. This emphasis has been enhanced by significant public health issues, such as SARS, and H1N1, and particularly COVID. In addition to human health security, infectious diseases of animals and plants are defined as an element of biosecurity (Fisher et al. 2012). In this sense, agricultural plants can potentially contract infectious diseases. This might lead to a decrease in agricultural productivity, affecting the stability and security of the food supply. However, biodiversity governance focuses on ensuring the diversity of genetical resources and species including agricultural products. IAS might be a threat to the survival of local agricultural plants, triggering concerns about food security. While biosecurity and biodiversity have different implications for policymakers, they converge on issues of food security.

\subsection{Obstacles to the convergence}

Although linkages between biosecurity and biodiversity can be identified, divergence remains undeniable. This article identifies three obstacles to convergence: redefining biological security; various understandings of biodiversity governance; and weak global governance on biosecurity and biodiversity issues.

Biological security has been redefined to include various issues beyond ecological security. It covers public health crises, ecological conservation, terrorist attacks, food security, and science and technology. This wide range of issues creates a gap 
between biosecurity and biodiversity governance. While biodiversity requires environmental agencies to assume a lead role, biosecurity must be addressed across various governmental agencies, including public health, national defense, and agricultural affairs. In addition, the relationship between biological threats and biological security embedded in the concept of biosecurity remain vague. As Liu (2020) states, while species and genetical resources can be defined as the objectives of biological security, topics related to viruses and bacteria, such as antimicrobial resistance, are identified as biological threats. Biological security requires governmental actions and policies to secure the objective materials, while biological threats are targets to be contained, managed, and even eliminated. Biodiversity governance requires substantial conservation action, a fundamental difference compared with the management of biological threats.

Various interpretations of biodiversity governance reveal significant differences with respect to the governance of biological security. Biodiversity has witnessed the development of various, competing, and controversial concepts, such as ecosystem service, and it thus has been described as the politics of knowledge (Vadrot 2014). Biodiversity governance has more or less been framed as scientific uncertainties and this raises the importance of precautionary actions (Scott 2016). Following the competing concepts of knowledge and scientific findings, the international negotiations of biodiversity conservation encounter contentious themes and political disputes. The Kunming Biodiversity Conference recognized gaps among positions on species, protected areas and Digital Sequence Information (DSI), and access and benefitsharing (ABS), particularly between developed and developing countries (Liu 2021). Various and competing understandings of biodiversity governance causes confusion regarding the concept of biological security. For example, biosecurity governance has a clear task of conserving genetic and biological resources. However, global biodiversity governance shows a complicated debate over resource management. The owners and providers of the resources have their own authorities to conserve and manage them, which are rooted in the principle of national sovereignty. Users focus on their access to the resources while they are required to share the benefits of having them. Because of this, a market-based approach has been designed to establish a mechanism for access and benefit-sharing (ABS) (Richerzhagen 2011). Not surprisingly, ABS has been a controversial topic of biodiversity governance.

Weak global biological governance creates difficulties with respect to the convergence of biosecurity and biodiversity. A lack of a strong and effective global biodiversity governance is caused by a gap between developed and developing countries, a gap between resources owners and users, fragmentation of international institutions, weak national capabilities, and insufficient public awareness (Wang 2021). However, the Kunming Conference laid a solid foundation for an ambitious global framework of biodiversity conservation, including through the Kunming Declaration and the 2050 Vision for Biodiversity. In contrast to the established international institutions of biodiversity conservation, global biosecurity governance requires a coherent framework for institutionalizing the various ways of addressing biosecurity concerns. International institutions and agreements of biosecurity have been framed and arranged separately across the United Nations Environment Programme (biosafety), Food and Agricultural Organization (food security), World Health 
Organization (pandemics) and the UN Office for Disarmament Affairs (biological weapons). The involvement of various international agencies demonstrates a great step towards raising public awareness. But it is important to bridge the gaps between various political priorities among the agencies and to minimize their competing ideas. Therefore, a coherent framework for biosecurity requires more discussions that include many stakeholders around the world.

\section{Policy implications}

Recognizing the importance and limitations of global biosecurity governance requires global consensus. In addition to the fragmented international institutional arrangements, biosecurity governance has been framed and constructed differently across different countries (Qin and Sun 2019). For example, in 2018, the UK released its "Biological Security Strategies," identifying the potential threats of public health crises, biological attacks, and infectious plant and animal diseases (UK 2018). The US has prioritized biological defense as a key focus of its national biosecurity strategy (USDHS 2017). These strategies are in sharp contrast to that of China, which covers a much wider range of security concerns. Therefore, it is important to establish dialogues to create a shared understanding of biosecurity across different countries.

Upgrading global biodiversity governance would contribute substantially to improving environmental and climate governance. The CBD plays a key role in facilitating international negotiations and global biodiversity governance. However, biodiversity conservation is not a single issue-it involves complex and various challenges. Actions related to conserving biodiversity have a positive impact on climate actions and have benefitted from other global environmental actions (Singh 2008).

Identifying the links between biosecurity and biodiversity is a fundamental requirement for relevant institutional arrangements. While biosecurity and biodiversity have been identified as converging and diverging over time, they can be addressed in a coherent and collective way. As discussed above, the concerns about species and genetic diversity and food security are shared by biosecurity and biodiversity governance. For example, food security concerns caused by IAS can be framed as a distinctive challenge of biosecurity and biodiversity beyond the agricultural issues.

Enhancing the role of China in global governance would be a significant step toward linking the biosecurity and biodiversity on a global scale. Since China made a commitment to host the Kunming Biodiversity Conference and has pledged to achieve carbon neutrality by 2060, it has been playing an important role in upgrading global environmental and ecological governance. China is an important owner and provider of biological resources, and a proactive actor in improving global biodiversity governance. In terms of biosecurity, China has made national laws and regulations to address various biological challenges. It is important to incorporate China's voice in efforts to improve global governance, particularly to represent the interests and concerns of developing countries. 


\section{Conclusion}

This article raises a discursive approach to observing the evolution of biosecurity and biodiversity governance in China. The approach of securitization facilitates efforts to map the process of politicalizing and securitizing biosecurity and biodiversity of China. This analysis concludes that biological governance has been constructed from ecological security to biological security while biodiversity governance was originally categorized as ecological security and was later framed as including various security concerns such as biological security. It is argued that biosecurity and biodiversity have converged and diverged over time in China. Genetic resources, species, and food security are the shared focuses between biosecurity and biodiversity. However, the boundary between the two remains. In this sense, the various focuses of each could have different implications for policymakers and stakeholders.

This article highlights the importance of linking biosecurity and biodiversity while recognizing the limitations and difficulties of doing so. Further study is required to understand and explore the convergence and divergence across countries outside China. And, it is important to clarify how and why different countries have traversed various paths to the securitization of biosecurity and biodiversity.

Funding The Funding was provided by Fundamental Research Funds for the Central Universities [Grant no. 3162019ZYKD10].

\section{Declarations}

Conflict of interest The author declares that there are no known competing financial interests or personal relationships that could have appeared to influence the work reported in this paper.

\section{References}

ADB. 2021. China shows a way forward to biodiversity conservation post-2020. https://www.adb.org/ news/op-ed/china-shows-way-forward-biodiversity-conservation-post-2020-niu-zhiming. Accessed 13 Dec 2021.

Balzacq, Thierry. 2005. The three faces of securitization: political agency, audience and context. European Journal of International Relations 11: 171-201.

Buzan, Barry, Ole Wæver, and Jaap de Wilde. 1998. Security: A new framework of analysis. London: Lynne Rienner.

CBD. 2020. Aichi biodiversity targets. Strategic plan 2011-2020, Secretary of Convention on Biological Diversity.

CBD. 2021a. The cartagena protocol on biosafety. https://bch.cbd.int/protocol/. Accessed 14 Dec 2021.

CBD. 2021b. Ecological civilization: building a shared future for all life on Earth. Kunming Declaration, Secretary of Convention on Biological Diversity. https://www.cbd.int/doc/c/c2db/972a/fb32e0a277 bf1ccfff742be5/cop-15-05-add1-en.pdf. Accessed 14 Dec 2021.

CGTN. 2021. Migrating herd of wild Asian elephants in Yunnan takes a break. China Global Television Network. https://news.cgtn.com/news/2021-06-08/Herd-of-wild-Asian-elephants-in-SW-China-sYunnan-takes-a-break-10VugLV1sli/index.html. Accessed 10 Dec 2021.

FAO. 2002. Combating desertification in the Korqin sandy lands through integrated afforestation. Forestry Research, Planning and Development in the Three North Region of China. 
Fisher, Matthew, Daniel Henk, Cheryl Briggs, John Brownstein, Lawrence Madoff, Sarah McCraw, and Sarah Gurr. 2012. Emerging fungal threats to animal, plant and ecosystem health. Nature 484: 186-194.

Liu, Yuejin. 2020. Biological security and threats within contemporary national security systems. Frontiers 20: 46-57.

Liu, Zhe. 2021. Situation and implications of the negotiations on the convention on Biological Diversity. International Economic Review 153: 155-176.

MEP. 2014. China's fifth national report on the implementation of the convention on biological diversity, Ministry of Environmental Protection of China.

Qin, Qin, and Sun Youhai. 2019. A global biosafety strategy research framework with specific implications for China. Journal of Biosafety and Biosecurity 1: 105-112.

Qin, Tianbao. 2020. Legal positioning and implementation of Biosecurity Law. Social Sciences Journal 3: $134-147$.

Richerzhagen, Carmen. 2011. Effective governance of access and benefit-sharing under the Convention on Biological Diversity. Biodiversity and Conservation 20: 2243-2261.

SCIO. 2021. Biodiversity conservation in China. The State Council Information Office of China.

Scott, Deborah. 2016. Framing and responding to scientific uncertainties: biofuels and synthetic biology at the convention on biological diversity. Jurimetrics 56: 245 .

Shim, Jae-Mahn., and Eunjung Shin. 2020. Drivers of ratification rates in global biodiversity governance: local environmentalism, orientation toward global governance, and peer pressure. Environmental Politics 29: 845-865.

Singh, Prati. 2008. Exploring biodiversity and climate change benefits of community-based forest management. Global Environmental Change 18: 468-478.

Stoett, Peter. 2010. Framing bioinvasion: biodiversity, climate change, security, trade, and global governance. Global Governance 16: 103-120.

UK. 2018. UK biological security strategy. https://assets.publishing.service.gov.uk/government/uploa ds/system/uploads/attachment_data/file/730213/2018_UK_Biological_Security_Strategy.pdf. Accessed 10 Oct 2021.

UNEP. 2020a. A crunch year for the biodiversity and climate emergencies. https://www.unep.org/newsand-stories/story/2020b-crunch-year-biodiversity-and-climate-emergencies. Accessed 12 Oct 2021.

UNEP. 2020b. Biosecurity law of the People's Republic of China. https://leap.unep.org/countries/cn/natio nal-legislation/biosecurity-law-peoples-republic-china. Accessed 12 Oct 2021.

USDHS. 2017. Biological security. The US deparment of homeland security. https://www.dhs.gov/topic/ biological-security. Accessed 2 Dec 2021.

Vadrot, Alice. 2011. Endangered species, biodiversity and the politics of conservation. In Global environmental politics: concepts, theories and case studies, eds. Gabriela Kutting, and Kyle Herman. Routledge.

Vadrot, Alice. 2014. The politics of knowledge and global biodiversity. Routledge.

Wang, Canfa, and Wenxuan Yu. 2003. Principles of international laws for biological security. Modern Law Science 25: 128-139.

Wang, Sidan. 2020. Fragmentation in security construction of biodiversity issue. Journal of International Security Studies 38: 127-156.

Wang, Sidan. 2021. Dilemma, motivations and prospects for upgrading global biodiversity governance. Yuejiang Academic Journal 13: 15-28.

Wang, Xiaoli. 2020. Era of biological security: transformation of new biotechnology and national security governance. International Security Studies 38: 29.

Zhang, Jin. 2004. Biological security issues and our responses. Social Sciences 9: 6.

Zhou, Yuanyuan. 2004. Biological security from the view of non-traditional security. Xiandai Guoji Guanxi 4: 17-23. 